\title{
Hanna KopCZyŃSKa-KŁos
}

Fundacja Kultury i Dziedzictwa Ormian Polskich, Warszawa

\author{
PROJEKTY GENEALOGICZNE \\ FUNDACJI KULTURY I DZIEDZICTWA ORMIAN POLSKICH
}

\section{„Mała ojczyzna” polskich Ormian}

Badania genealogiczne nad rodami ormiańskimi znajdują się w kręgu zainteresowań Fundacji Kultury i Dziedzictwa Ormian Polskich od samego początku jej istnienia. Cele statutowe Fundacji: zarządzanie dziedzictwem, troska o to dziedzictwo oraz upowszechnianie kultury i historii Ormian polskich, w naturalny sposób ukierunkowują jej działania na realizację projektów genealogicznych skierowanych do szerokiego grona odbiorców.

Znaczenie genealogii dla wiedzy historycznej, przez lata lekceważone, dopiero stosunkowo od niedawna zaczyna zajmować należne miejsce wśród nauk pomocniczych historii. Jednocześnie intensywnie i z dużym powodzeniem rozwijają się poszukiwania, które można określić mianem amatorskich, a które niezwykle wzbogacają i indywidualizują akademickie prace badawcze. Być może przyczynia się do tego nieustający rozwój i coraz większy dostęp do nowoczesnych technologii informatycznych, co znacznie ułatwia, praktycznie każdemu, aktywne uczestnictwo w badaniu historii swojej rodziny i odtwarzaniu pamięci własnych przodków. „Odkurzone” dzieje rodzinne składają się na historie lokalne i historie pewnych społeczności, których pamięć pozwala na zachowanie tradycji i tożsamości.

Taką społecznością poszukującą w genealogiach swojej tożsamości są polscy Ormianie, których „mała ojczyzna” to przede wszystkim ośrodki na Kresach dawnej Rzeczypospolitej, takie jak Lwów, Kuty czy Stanisławów. Tam, dzięki istnieniu parafii ormiańskokatolickich, tradycje przodków przetrwały najdłużej. Ale to także wiele innych większych i mniejszych ośrodków miejskich, osad 
i wsi polskich, gdzie działalność Ormian i ich potomków zapisała się trwale, wzbogacając karty historii Polski. Nad materialnym dziedzictwem kulturowym polskich Ormian, gromadzonym przez wieki w tych miejscach, czuwa dziś Fundacja Kultury i Dziedzictwa Ormian Polskich z siedzibą w Warszawie. Dzięki temu dziedzictwu badania i projekty genealogiczne przybierają nowy, bardziej zaawansowany wymiar.

\section{Księgi metrykalne}

W Archiwum Polskich Ormian (APO), zarządzanym przez Fundację, zgromadzono materiały archiwalne pochodzące z parafii ormiańskokatolickich na Kresach, które trafiły do Polski po II wojnie światowej. Wśród wielu archiwaliów znajduje się 46 ksiąg metrykalnych chrztów, małżeństw, zgonów i zapowiedzi przedślubnych oraz skorowidzów do ksiąg z lat 1700-1953 . Są to źródła bezcenne dla prowadzenia poszukiwań genealogicznych i odtwarzania rodzinnych historii. Wszystkie księgi zostały zdigitalizowane zgodnie ze standardami Naczelnej Dyrekcji Archiwów Państwowych (2778 skanów) i są dostępne on-line w portalu www.szukajwarchiwach.pl ${ }^{2}$. Każdy zainteresowany dziejami rodziny może osobiście „dotykać” zdigitalizowanych kart, zbierając informacje do własnego drzewa genealogicznego.

Przed II wojną światową w granicach Polski znajdowało się osiem parafii ormiańskokatolickich (Brzeżany, Horodenka, Kuty, Lwów, Łysiec, Stanisławów, Śniatyn i Tyśmienica), wchodzących w skład archidiecezji lwowskiej obrządku ormiańskiego. Parafie w Czerniowcach i Suczawie (powstałe w XIX wieku, za czasów monarchii austrowęgierskiej) znalazły się na terenie Rumunii. W APO znajduje się największy zbiór ormiańskich ksiąg metrykalnych. Najwięcej, siedemnaście, pochodzi z parafii w Stanisławowie, dziesięć z Horodenki, po kilka z parafii w Kutach, Łyścu, Czerniowcach i Tyśmienicy. Jest to jednak tylko część z wytworzonych niegdyś i zachowanych do dziś źródeł tego gatunku. Pozostałe księgi uległy rozproszeniu i przechowywane są w archiwach i bibliotekach polskich, ukraińskich i ormiańskich, część została zniszczona lub miejsca ich przechowywania nie udało się do tej pory ustalić. Fundacja przez cały czas prowadzi poszukiwania zaginionych ksiąg metrykalnych oraz pozyskuje kopie cyfrowe tych, które odnaleziono w zasobach innych archiwów. Poniższe zestawienia przedstawiają ustalone miejsca przechowywania ormiańskokatolickich ksiąg metrykalnych w Polsce (10) i za granicą (17).

${ }^{1}$ Archiwum Polskich Ormian, Zbiór ksiag stanu cywilnego i zapowiedzi przedślubnych parafii ormiańskokatolickich z dawnych Kresów Rzeczpospolitej, sygn. 1-46. Zbiór został zinwentaryzowany w Zintegrowanym Systemie Informacji Archiwalnej (ZoSIA).

${ }^{2}$ https://szukajwarchiwach.pl/345/9/0/?q=XARCHro:345+XTYPEro:zesp\&order=syg_ order\&wynik=4\&rpp=15\&page=1\#tabZespol, 30 VIII 2018. 
Tab. 1. Księgi metrykalne Kościoła ormiańskokatolickiego w archiwach polskich

\begin{tabular}{|c|c|c|c|c|}
\hline L.p. & PARAFIA & KSIĘGA / TYTUŁ & $\begin{array}{c}\text { MIEJSCE } \\
\text { PRZECHOWYWANIA }\end{array}$ & $\begin{array}{c}\text { ZESPÓŁ, } \\
\text { SYGNATURA }\end{array}$ \\
\hline 1. & Czerniowce & $\begin{array}{l}\text { Księga ochrzczonych } \\
1836-1890\end{array}$ & $\begin{array}{l}\text { Archiwum Archidie- } \\
\text { cezjalne w Poznaniu }\end{array}$ & PMB 003/01 \\
\hline 2. & Czerniowce & $\begin{array}{l}\text { Księga ochrzczonych } \\
1895-1944\end{array}$ & $\begin{array}{l}\text { Archiwum Archidie- } \\
\text { cezjalne w Poznaniu }\end{array}$ & PMB 003/05 \\
\hline 3. & Czerniowce & $\begin{array}{l}\text { Księga zaślubionych } \\
1837-1932\end{array}$ & $\begin{array}{l}\text { Archiwum Archidie- } \\
\text { cezjalne w Poznaniu }\end{array}$ & PMB 003/03 \\
\hline 4. & Czerniowce & $\begin{array}{l}\text { Księga zaślubionych } \\
1933-1939\end{array}$ & $\begin{array}{l}\text { Archiwum Archidie- } \\
\text { cezjalne w Poznaniu }\end{array}$ & PMB 003/04 \\
\hline 5. & Czerniowce & $\begin{array}{l}\text { Księga zmarłych 1837- } \\
1915\end{array}$ & $\begin{array}{l}\text { Archiwum Archidie- } \\
\text { cezjalne w Poznaniu }\end{array}$ & PMB 003/05 \\
\hline 6. & Czerniowce & $\begin{array}{l}\text { Księga zmarłych 1916- } \\
1944\end{array}$ & $\begin{array}{l}\text { Archiwum Archidie- } \\
\text { cezjalne w Poznaniu }\end{array}$ & PMB 003/06 \\
\hline 7. & Stanisławów & $\begin{array}{l}\text { Księga metrykalna } \\
\text { urodzeń 1837-1914 }\end{array}$ & $\begin{array}{l}\text { Archiwum Główne } \\
\text { Akt Dawnych w War- } \\
\text { szawie }\end{array}$ & $\begin{array}{l}\text { Księgi metrykalne } \\
\text { i akta parafii i gmin } \\
\text { różnych wyznań i ob- } \\
\text { rządków (Ormianie, } \\
\text { Autokefaliczna Cer- } \\
\text { kiew Prawosławna, } \\
\text { baptyści, mennonici, } \\
\text { ewangeliczni chrze- } \\
\text { ścijanie) z terenów } \\
\text { tzw. zabużańskich, } \\
\text { sygn. } 16\end{array}$ \\
\hline 8. & Stanisławów & $\begin{array}{l}\text { Księga metrykalna } \\
\text { zgonów 1837-1932 }\end{array}$ & $\begin{array}{l}\text { Archiwum Główne } \\
\text { Akt Dawnych w War- } \\
\text { szawie }\end{array}$ & $\begin{array}{l}\text { Księgi metrykalne } \\
\text { i akta parafii i gmin } \\
\text { różnych wyznań i ob- } \\
\text { rządków (Ormianie, } \\
\text { Autokefaliczna Cer- } \\
\text { kiew Prawosławna, } \\
\text { Baptyści, Mennonici, } \\
\text { Ewangeliczni Chrze- } \\
\text { ścijanie) z terenów } \\
\text { tzw. zabużańskich, } \\
\text { sygn. } 18\end{array}$ \\
\hline 9. & Śniatyn & $\begin{array}{l}\text { Liber copulatorum } \\
\text { ecclesiae parochialis } \\
\text { Sniatynensis rit[us] } \\
\text { Armeni, 1786-1866 }\end{array}$ & $\begin{array}{l}\text { Archiwum Archidie- } \\
\text { cezjalne w Przemyślu }\end{array}$ & \\
\hline
\end{tabular}




\begin{tabular}{|c|c|c|c|c|}
\hline L.p. & PARAFIA & KSIĘGA / TYTU & $\begin{array}{c}\text { MIEJSCE } \\
\text { PRZECHOWYWANIA }\end{array}$ & $\begin{array}{c}\text { ZESPÓt, } \\
\text { SYGNATURA }\end{array}$ \\
\hline 10. & Śniatyn & $\begin{array}{l}\text { Index alphabeticus co- } \\
\text { pulatorum, natorum } \\
\text { et mortuorum ecclesia } \\
\text { parochialis Sniatynen- } \\
\text { sis, 1786-1834 }\end{array}$ & $\begin{array}{l}\text { Archiwum Archidie- } \\
\text { cezjalne w Przemyślu }\end{array}$ & \\
\hline 11. & Złoczów ${ }^{3}$ & $\begin{array}{l}\text { Księga metrykalna } \\
\text { urodzeń 1685-1787, } \\
\text { ślubów 1693-1784, } \\
\text { zgonów 1694-1784 }\end{array}$ & $\begin{array}{l}\text { Archiwum Główne } \\
\text { Akt Dawnych w War- } \\
\text { szawie }\end{array}$ & $\begin{array}{l}\text { Księgi metrykalne } \\
\text { i akta parafii i gmin } \\
\text { różnych wyznań i ob- } \\
\text { rządków (Ormianie, } \\
\text { Autokefaliczna Cer- } \\
\text { kiew Prawosławna, } \\
\text { baptyści, mennonici, } \\
\text { ewangeliczni chrze- } \\
\text { ścijanie) z terenów } \\
\text { tzw. zabużańskich, } \\
\text { sygn. } 1\end{array}$ \\
\hline
\end{tabular}

Tab. 2. Księgi metrykalne Kościoła ormiańskokatolickiego w archiwach i bibliotekach zagranicznych

\begin{tabular}{|c|c|c|c|c|}
\hline L.p. & PARAFIA & KSIĘGA /TYTUŁ/ & $\begin{array}{c}\text { MIEJSCE } \\
\text { PRZECHOWYWANIA }\end{array}$ & $\begin{array}{c}\text { ZESPÓt, } \\
\text { SYGNATURA }\end{array}$ \\
\hline 1. & Brzeżany & $\begin{array}{l}\text { Liber copulatorum eccle- } \\
\text { siae parochialis Brzezanen- } \\
\text { sis ritus Armeni ab anno } \\
1786, \text { t. } 1-2,1786-1905\end{array}$ & $\begin{array}{l}\text { Instytut Dawnych Ręko- } \\
\text { pisów Matenadaran im. } \\
\text { Mesroba Masztoca w Ery- } \\
\text { waniu }\end{array}$ & \\
\hline 2. & Brzeżany & $\begin{array}{l}\text { Elenchus eorum qui tem- } \\
\text { pore conflagrata ecclesiae } \\
\text { parochialis Brzezanenesis } \\
\text { rit[us] Ar[meni] in ecclesia } \\
\text { parochiali Brzezanensi } \\
\text { cui cura animarum rit[us] } \\
\text { Ar[meni] commissa fuerat } \\
\text { ab anno } 181020 \text { x[=de- } \\
\text { cem]bris ad annum [1]827 } \\
\text { baptisati sunt, } 1810-1827\end{array}$ & $\begin{array}{l}\text { Instytut Dawnych Ręko- } \\
\text { pisów Matenadaran im. } \\
\text { Mesroba Masztoca w Ery- } \\
\text { waniu }\end{array}$ & \\
\hline
\end{tabular}

${ }^{3}$ Parafia ormiańska w Złoczowie istniała do roku 1787 i skupiała Ormian, którzy przybyli do miasta po zdobyciu Jazłowca przez Turków w 1676 roku. 


\begin{tabular}{|c|c|c|c|c|}
\hline L.p. & PARAFIA & KSIĘGA /TYTUŁ/ & $\begin{array}{c}\text { MIEJSCE } \\
\text { PRZECHOWYWANIA }\end{array}$ & $\begin{array}{c}\text { ZESPÓŁ, } \\
\text { SYGNATURA }\end{array}$ \\
\hline 3. & Brzeżany & $\begin{array}{l}\text { Liber baptisatorum eccle- } \\
\text { siae parochialis Brzezanen- } \\
\text { sis ritus Armeni ab anno } \\
828 \text { die } 11 \text { septemb[ris] ad } \\
\text { annum } 1899, \text { t. } 2,1828- \\
1899\end{array}$ & $\begin{array}{l}\text { Instytut Dawnych Ręko- } \\
\text { pisów Matenadaran im. } \\
\text { Mesroba Masztoca w Ery- } \\
\text { waniu }\end{array}$ & \\
\hline 4. & Brzeżany & $\begin{array}{l}\text { Liber mortuorum ecclesiae } \\
\text { parochialis Brzezanensis } \\
\text { ritus Armeni ab anno } 1829 \\
\text { die } 11 \text { Septemb[ris], t. 1, } \\
\text { 1828-1906 } \\
\end{array}$ & $\begin{array}{l}\text { Instytut Dawnych Ręko- } \\
\text { pisów Matenadaran im. } \\
\text { Mesroba Masztoca w Ery- } \\
\text { waniu }\end{array}$ & \\
\hline 5. & Brzeżany & $\begin{array}{l}\text { Выписки из метричних } \\
\text { книг про смерть } \\
\text { парафян м[іста] } \\
\text { Бережани, 1869-1889 }\end{array}$ & $\begin{array}{l}\text { Centralne Państwowe } \\
\text { Archiwum Historyczne } \\
\text { Ukrainy we Lwowie }\end{array}$ & $\begin{array}{l}\text { Фонд } \\
475 / 282\end{array}$ \\
\hline 6. & Czerniowce & $\begin{array}{l}\text { Метрична книга про } \\
\text { народження, одружения } \\
\text { смерть парафіян м[іста] } \\
\text { Чернівці, 1881-1893 }\end{array}$ & $\begin{array}{l}\text { Centralne Państwowe } \\
\text { Archiwum Historyczne } \\
\text { Ukrainy we Lwowie }\end{array}$ & $\begin{array}{l}\text { Фонд } \\
475 / 290\end{array}$ \\
\hline 7. & Horodenka & $\begin{array}{l}\text { Метрична книга про } \\
\text { народження, одружения } \\
\text { смерть парафіян м[іста] } \\
\text { Городенка, 1868-1897 }\end{array}$ & $\begin{array}{l}\text { Centralne Państwowe } \\
\text { Archiwum Historyczne } \\
\text { Ukrainy we Lwowie }\end{array}$ & $\begin{array}{l}\text { Фонд } \\
475 / 283\end{array}$ \\
\hline 8. & Horodenka & $\begin{array}{l}\text { Метрична книга косте- } \\
\text { лу реєстрачії народжень, } \\
\text { [1784] 1850-1885 }\end{array}$ & $\begin{array}{l}\text { Archiwum Państwowe } \\
\text { Obwodu Iwano-Frankiw- } \\
\text { skiego }\end{array}$ & $\begin{array}{l}\text { Фонд } \\
631 / 116\end{array}$ \\
\hline 9. & Horodenka & $\begin{array}{l}\text { Метрична книга про } \\
\text { шлюб за 1787-1869 роки } \\
\text { черква міста Городенка, } \\
\text { 1784-1874 }\end{array}$ & $\begin{array}{l}\text { Archiwum Państwowe } \\
\text { Obwodu Iwano-Frankiw- } \\
\text { skiego }\end{array}$ & $\begin{array}{l}\text { Фонд } \\
631 / 117\end{array}$ \\
\hline 10. & Kuty & $\begin{array}{l}\text { Метрична книга про } \\
\text { смерть парафіян с[ела] } \\
\text { Кути, 1868-1894 }\end{array}$ & $\begin{array}{l}\text { Centralne Państwowe } \\
\text { Archiwum Historyczne } \\
\text { Ukrainy we Lwowie } \\
\end{array}$ & $\begin{array}{l}\text { Фонд } \\
475 / 284\end{array}$ \\
\hline 11. & Kuty & $\begin{array}{l}\text { Książka zapowiedzi w pa- } \\
\text { rafii kuckiej ob[rzq̨dku] } \\
\text { ormiańskiego od } 1860 \text { roku } \\
\text { dnia } 19 \text { stycznia, [do roku } \\
\text { 1892] }\end{array}$ & $\begin{array}{l}\text { Archiwum Archidiecezji } \\
\text { Lwowskiej }\end{array}$ & Cern VII 5/1 \\
\hline 12. & Lwów & $\begin{array}{l}\text { Metryka kościoła ormiań- } \\
\text { skiego roku } 1636 \text { (księga } \\
\text { ochrzczonych, zaślubio- } \\
\text { nych, zmarłych prowadzo- } \\
\text { no przy katedrze do roku } \\
1732 \text { ) }\end{array}$ & $\begin{array}{l}\text { Biblioteka Klasztoru Me- } \\
\text { chitarystów w Wiedniu }\end{array}$ & 440 \\
\hline
\end{tabular}




\begin{tabular}{|c|c|c|c|c|}
\hline L.p. & PARAFIA & KSIĘGA /TYTUŁ/ & $\begin{array}{c}\text { MIEJSCE } \\
\text { PRZECHOWYWANIA }\end{array}$ & $\begin{array}{c}\text { ZESPÓt, } \\
\text { SYGNATURA }\end{array}$ \\
\hline 13. & Lwów & $\begin{array}{l}\text { Метрична книга } \\
\text { Вірменського собору про } \\
\text { народження парафіян, } \\
1777-1893 \\
\end{array}$ & $\begin{array}{l}\text { Centralne Państwowe } \\
\text { Archiwum Historyczne } \\
\text { Ukrainy we Lwowie }\end{array}$ & $\begin{array}{l}\text { Фонд } \\
475 / 286\end{array}$ \\
\hline 14. & Łysiec & $\begin{array}{l}\text { Метрична книга про } \\
\text { народження, одружения, } \\
\text { смерть парафіян } \\
\text { м[істеч]ка Лисець, 1869- } \\
1891\end{array}$ & $\begin{array}{l}\text { Centralne Państwowe } \\
\text { Archiwum Historyczne } \\
\text { Ukrainy we Lwowie }\end{array}$ & $\begin{array}{l}\text { Фонд } \\
475 / 285\end{array}$ \\
\hline 15. & Stanisławów & $\begin{array}{l}\text { Метрична книга про } \\
\text { народження, одружения, } \\
\text { смерть парафіян } \\
\text { м[іста] Станіславів, } \\
\text { 1880-1893 }\end{array}$ & $\begin{array}{l}\text { Centralne Państwowe } \\
\text { Archiwum Historyczne } \\
\text { Ukrainy we Lwowie }\end{array}$ & $\begin{array}{l}\text { Фонд } \\
475 / 287\end{array}$ \\
\hline 16. & Suczawa & $\begin{array}{l}\text { Метрична книга про } \\
\text { народження, одружения, } \\
\text { смерть парафіян м[іста] } \\
\text { Сучава, 1833-1900 }\end{array}$ & $\begin{array}{l}\text { Centralne Państwowe } \\
\text { Archiwum Historyczne } \\
\text { Ukrainy we Lwowie }\end{array}$ & $\begin{array}{l}\text { Фонд } \\
475 / 288\end{array}$ \\
\hline 17. & Tyśmienica & $\begin{array}{l}\text { Метрична книга та } \\
\text { виписки з свідецтв } \\
\text { парафіян м[іста] } \\
\text { Тисьмениця }\end{array}$ & $\begin{array}{l}\text { Centralne Państwowe } \\
\text { Archiwum Historyczne } \\
\text { Ukrainy we Lwowie }\end{array}$ & $\begin{array}{l}\text { Фонд } \\
475 / 289\end{array}$ \\
\hline
\end{tabular}

\section{Indeksacja i tłumaczenia}

Ze względu m.in. na ograniczenia prawne w udostępnianiu pozyskanych kopii materiałów archiwalnych Fundacja stara się zapewnić dostęp przynajmniej do treści źródeł genealogicznych, prowadząc indeksację ksiąg metrykalnych. Dotyczy to także ksiąg z zasobu APO, których skany są udostępnione, jednak indeksacja stanowi o wiele prostszą w obsłudze możliwość dotarcia do informacji, bez konieczności czasochłonnego wertowania oryginałów, w większości spisanych po łacinie, a niekiedy w językach kipczackim i ormiańskim.

Indeksy ksiąg metrykalnych, zawierające najważniejsze dane $\mathrm{z}$ zapisów o udzieleniu kościelnych sakramentów, dostępne są w wyszukiwarce Wirtualnego Archiwum Polskich Ormian (WAPO) ${ }^{4}$. Do tej pory zindeksowano $37 \mathrm{ksiąg}$ i ekstraktów z ksiąg metrykalnych. Wciąż czynione są starania, aby co roku pojawiały się nowe indeksy. Od pewnego czasu do danego pojedynczego rekordu w indeksie dołączany jest odpowiedni fragment księgi. W ten sposób, za pomocą wyszukiwarki, użytkownik ma możliwość zapoznania się także z oryginałem za-

\footnotetext{
${ }^{4}$ http://www.archiwum.ormianie.pl/archiwumk.php
} 
pisu metrykalnego. W WAPO dostępne są też tłumaczenia trzech narracyjnych ksiąg metrykalnych pochodzących z parafii stanisławowskiej ${ }^{5}$.

\section{Cmentarze on-line}

Stare cmentarze - nieocenione źródło do badań genealogicznych, nierzadko są niszczone i zapomniane, często ulegają w końcu całkowitej degradacji. Jeśli znikną, nie uda się ocalić pamięci o osobach, które są na nich pochowane. Dokumentacja grobów, tworzona na podstawie zachowanych nagrobków oraz materiałów archiwalnych, znajduje ważne miejsce wśród projektów Fundacji. Wszystkie wyniki prac udostępniane są w Internecie szerokiemu gronu użytkowników.

W WAPO pojawiła się nowa zakładka Cmentarze online, pod którą można znaleźć zakładkę Warszawa - Stare Powazki. Na podstawie badań historycznych, kwerend archiwalnych i indeksacji cmentarnej zostały zgromadzone tu informacje o Ormianach i ich potomkach pochowanych na Cmentarzu Powązkowskim (249 osób), zawierające m.in. lokalizator grobów, ich fotografie, dokładne opisy oraz życiorysy zmarłych. Ormiańskie Stare Powazki to także plan w wersji papierowej z oznaczonymi kwaterami, wykazem pochowanych tam osób, fotografiami nagrobków i dokładną lokalizacją GPS ${ }^{6}$. Strona WAPO została też rozbudowana o nową wyszukiwarkę Pochowani na cmentarzach. Dostępne są tam dane dotyczące osób pochodzenia ormiańskiego z Cmentarza Powązkowskiego i części Cmentarza Łyczakowskiego we Lwowie ${ }^{7}$.

\section{Drzewo polskich Ormian, biogramy i fotografie}

Każdy Ormianin, krewny, powinowaty czy potomek Ormian, może udostępnić na stronie www.skarbnica.ormianie.pl własny wywód genealogiczny w dowolnej postaci. Jednocześnie Fundacja, bazując na kwerendach archiwalnych i prasowych, tradycji ustnej i udostępnionych zapiskach rodzinnych, prowadzi własne badania. W ich efekcie i dzięki możliwościom profesjonalnego programu komputerowego powstaje drzewo genealogiczne polskich Ormian. Do chwili obecnej uwzględniono prawie pięć tysięcy osób w dziewięciu pokoleniach. Rezultaty

5 Są to: Liber secundus antiquus baptizatorum et confirmatorum, 1703-1783; Liber tertius baptizatorum et confirmatorum, 1783-1834; Liber defunctorum parochianorum Stanislanoviensium Armenorum, 1715-1829. Księgi te spisane zostały w sposób ciągły, narracyjny, a nie w rubrykach; tłumaczenia dostępne są on-line: www.archiwum.ormianie.pl, zakładka: Rękopisy i niezindeksowane księgi metrykalne. Księgi zostały przetłumaczone w ramach projektu „Ormianie w Stanisławowie - studium genealogiczne”, dofinansowanego przez Muzeum Historii Polski w 2014 roku.

${ }^{6}$ Projekt Ormiańskie Stare Powązki zrealizowano dzięki dofinansowaniu m. st. Warszawy w 2017 r.

${ }^{7}$ http://www.archiwum.ormianie.pl/archiwumc.php 
dostępne są na stronie: www.skarbnica.ormiane.pl, w zakładce: Poszukiwania genealogiczne . $^{8}$.

Pisząc o inicjatywach genealogicznych Fundacji, warto wspomnieć o ormiańskiej encyklopedii internetowej, czyli: www.Wiki.Ormianie.pl, która jest z nimi ściśle powiązana. Wiele biogramów powstaje dzięki wykorzystaniu wyników badań genealogicznych, np. w ramach wspomnianego projektu Ormiańskie Stare Powązki powstało 40 biogramów Ormian i ich potomków związanych z Warszawą. I odwrotnie: informacje genealogiczne można uzupełniać na podstawie danych zawartych w biogramach? .

Taki system „naczyń połączonych” dotyczy także fotografii zgromadzonych w Archiwum Polskich Ormian oraz kopii fotografii pochodzących ze zbiorów prywatnych, udostępnionych Fundacji. Dzięki kwerendom archiwalnym udaje się niejednokrotnie ustalić dane sportretowanych osób, a wykorzystując fotografie i pozostawione na rewersach opisy, można uzupełniać drzewo genealogiczne polskich Ormian. Projekty genealogiczne to najlepszy sposób na zachowanie dziedzictwa kulturowego w wymiarze osobistym, rodzinnym i lokalnym, a także na odkrywanie ormiańskiej „małej ojczyzny”. Dzięki nim jest możliwe poznanie nieznanych dotąd faktów biograficznych, dopisanie dat na nieczytelnych nagrobkach, odnajdywanie kropli krwi ormiańskiej wśród wielu polskich patriotów i osób zasłużonych. Realizacja projektów była i jest możliwa dzięki dotacjom Ministra Spraw Wewnętrznych i Administracji, Naczelnej Dyrekcji Archiwów Państwowych, m.st. Warszawy oraz Muzeum Historii Polski.



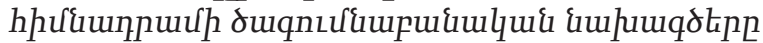

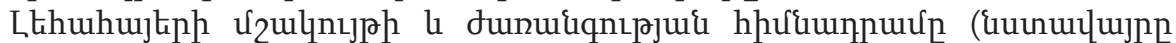



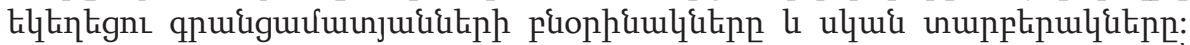

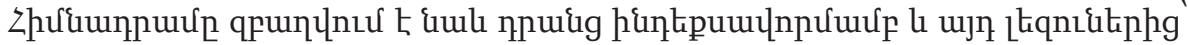

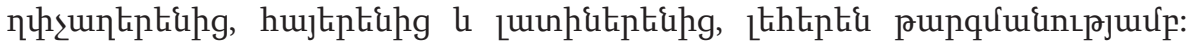

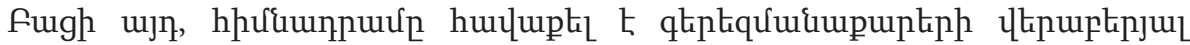

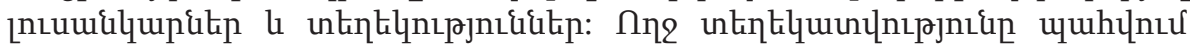

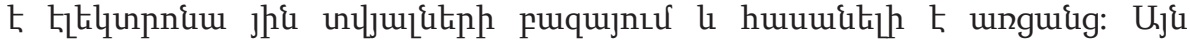

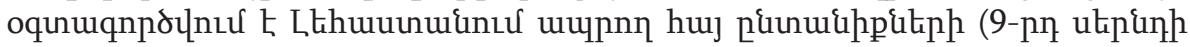

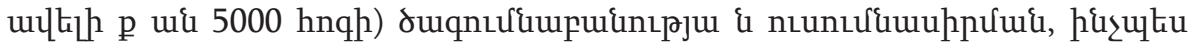

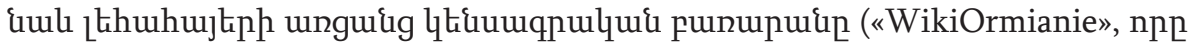

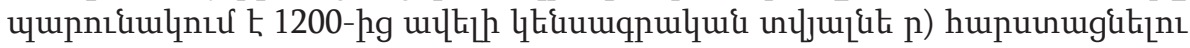
queuunulynı:

${ }^{8}$ Program umożliwia dołączanie m.in. fotografii. Produktem końcowym jest strona internetowa, którą można generować każdorazowo po uzupełnieniu drzewa o nowe wpisy.

9 www.Wiki.Ormianie.pl zawiera obecnie ponad 1200 biogramów. 


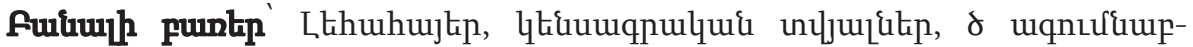

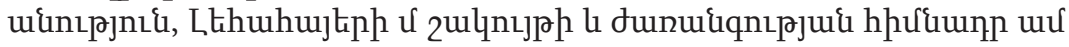

Hanna Kopczyńska-Kłos, Genealogical Projects of the Foundation of Culture and Heritage of Polish Armenians

The Foundation of the Culture and Heritage of Polish Armenians located in Warsaw collects both original and copied birth certificate registries dated at the times from $17^{\text {th }}$ to $20^{\text {th }}$ centuries and coming from Armenian Catholic parishes. The Foundation catalogues and translates them from Kipchak, Armenian and Latin into Polish. Additionally, it collects information on grave inscriptions and photographs. All data is being stored electronically and published online. It serves the purpose of compiling genealogical trees of Armenian families living in Poland (over 5000 people in 9 generations) and creating an online biographical dictionary of Polish Armenians (WikiOrmianie, over 1200 biograms).

Keywords: Polish Armenians, biography, genealogy, Foundation of Culture and Heritage of Polish Armenians 